\title{
Discutindo o Processo de Criação Científica por meio de uma Abordagem Histórica da Anatomia Humana em um Curso de Licenciatura em Ciências Biológicas
}

\section{Discussing the Process of Scientific Creation through a Historical Approach to Human Anatomy in a Pre-service Biology Teacher Education Course}

\author{
Gabriel Ribeiro ${ }^{\circledR}$ Brasil \\ José Luís de Jesus Coelho da Silva ${ }^{\circledR}$ Portugal
}

O objetivo desse estudo foi analisar o papel de uma estratégia de intervenção pedagógica focalizada na história da ciência na (re)construção de concepções de futuros professores sobre o processo de criação científica, considerado uma das várias dimensões da natureza da ciência. Trata-se de uma intervenção pedagógica centrada na abordagem histórica do sistema circulatório humano, desenvolvida e avaliada com um grupo de 22 alunos da disciplina Anatomia Humana, de um curso de Licenciatura em Ciências Biológicas. $\mathrm{Na}$ avaliação da intervenção empregou-se dois instrumentos de investigação, atividades de aprendizagem e roteiro da entrevista dos grupos focais, sendo que as respostas dos alunos às questões contidas nestes instrumentos foram analisadas por intermédio da análise de conteúdo. Os resultados da investigação indicam que a estratégia de intervenção pedagógica implementada contribuiu para que os alunos (re)construíssem suas concepções sobre o processo de criação científica, pois estes passaram a reconhecer a pluralidade de processos mobilizados pelos cientistas e a inexistência de um único método científico.

Palavras-chave: história da ciência; natureza da ciência; anatomia humana.

The objective of this study was to analyze the role of a pedagogical intervention strategy focused on the history of science related to the (re)development of conceptions about the process of scientific creation in future teachers, considered one of the several nature of science dimensions. It is about a pedagogical intervention focused on a historical approach to human circulatory system, developed and assessed with a group of 22 students of the Human Anatomy course of a Biology degree program. In the intervention assessment, two investigation instruments were applied, learning activities and an interview guide of the focus groups. The pre-service teachers' answers to the questions in these instruments were evaluated through content analysis. The results indicate that 
the pedagogical intervention strategy implemented supported students' redevelopment of their conceptions about the process of scientific creation, as they began to recognize the plurality of processes that are made by scientists and the nonexistence of a unique scientific method.

Keywords: history of science; nature of science; human anatomy.

\section{Introdução}

As contribuições da história da ciência para a (re)construção de concepções de futuros professores sobre dimensões da natureza da ciência têm sido objeto de substantiva consideração por parte dos investigadores no âmbito do ensino de ciências (ver, por exemplo, Abd-El-Khalick, 2005; Lin, \& Chen, 2002; Oki, \& Moradillo, 2008; Rudge, Cassidy, Fulford, \& Howe, 2013; Teixeira, Freire Junior, \& El-Hani, 2009). A realização de pesquisas neste campo sustenta-se, entre outros aspectos, no argumento de que os futuros professores de ciências devem ter uma maior compreensão sobre as dimensões da natureza da ciência, sendo a história da ciência um recurso para atingir tal meta. O papel da história da ciência na formação dos professores assenta não só no contributo para o desenvolvimento da compreensão acerca dos processos de produção do conhecimento científico, e dos conceitos associados aos mesmos, mas também no entendimento das concepções perfilhadas pelos alunos e das dificuldades por eles experienciadas durante a aprendizagem, permitindo aos professores idealizarem estratégias necessárias à superação destas (Giordan, 2011). Assim, a história da ciência pode se constituir como um recurso didático a ser mobilizado pelos professores de diferentes níveis educacionais. Deste modo, considera-se pertinente o desenvolvimento de investigações que analisem o potencial educativo da inserção da história da ciência nas diferentes disciplinas dos cursos de licenciatura, tendo em perspectiva a possibilidade deste tipo de abordagem transversalizar/perpassar o currículo da formação de professores de ciências favorecendo, também, a construção de imagens menos deformadas sobre o trabalho científico (Gil Pérez et al., 2001; Rivero, \& Wamba, 2011). Com base nestes aspectos, a presente pesquisa, desenvolvida em um curso de licenciatura, incide sobre a análise do impacto de uma estratégia de intervenção pedagógica, centrada na história da ciência e focalizada no processo de criação científica - dimensão da natureza da ciência associada a diferentes processos mobilizados pelos cientistas durante uma investigação, inclusive aos métodos que norteiam o trabalho de pesquisa (Coelho da Silva, 2007).

A palavra método (lat. tardio methodus, do gr. methodos, de meta: por, através de; e hodos: caminho) pode ser definida como o "conjunto de procedimentos racionais, baseados em regras que visam atingir um objetivo determinado" (Japiassú, \& Marcondes, 2001, p.130). No tocante à ciência, vários textos - livros didáticos, manuais de metodologia científica, páginas da internet etc. - ainda apontam a existência de uma suposta sequência nuclear de atividades, denominada de "o método científico". Este conjunto de atividades, descritivo e normativo, tem definido o que os "bons cientistas" 
fazem e, principalmente, estabelecido um padrão do que deve ser considerado como ciência, assim, servindo como um critério de demarcação (Woodcock, 2014).

A preocupação com a demarcação, por sua vez, encoraja (e é encorajada pela) a ideia de que a investigação científica real, o artigo genuíno, difere da investigação de outros tipos em virtude de seu método ou procedimento excepcionalmente eficaz - o suposto "método científico". Entretanto, ainda esperamos ver qualquer tipo de concordância a respeito de o que é, exatamente, esse presumível método (Haack, 2012, p. 87, tradução nossa).

Uma análise da história da ciência indica que métodos científicos desenvolveramse sob as contingências do cenário tecnológico, histórico-cultural e epistemológico vigente (Chalmers, 1993). Tal pluralismo metodológico, presente nas diversas ciências e evidenciado pela história, pode ser exemplificado pela seguinte listagem de métodos científicos descrita em Echeverría (1995): (a) métodos dedutivos e indutivos; (b) métodos de análise e de síntese; (c) métodos experimentais; (d) método axiomático; (e) métodos matemáticos; (f) métodos de observação; (g) métodos de medição; (h) métodos de classificação ou taxonomia; (i) métodos heurísticos; (j) método hipotético-dedutivo; (k) métodos computacionais; (l) métodos baseados na compreensão dos fenômenos estudados; (m) métodos hermenêuticos e contextuais; (n) métodos metacientíficos; (o) métodos de implementação técnica do conhecimento científico e construção de artefatos científicos.

No horizonte vislumbrado por Echeverría (1995), os filósofos da ciência não deveriam preocupar-se apenas com a pluralidade das ciências, mas, também, com a pluralidade metodológica de cada ciência. Nesse sentido, o autor exemplifica que filósofos de inspiração kantiana, assim como os de orientação neopositivista, consideram que a metodologia utilizada pelos matemáticos é exclusivamente lógico-dedutiva. Entretanto, isso não corresponde à prática real dos matemáticos, que recorrem, por exemplo, a métodos heurísticos e à experimentação, ou seja, a uma pluralidade metodológica. Tendo em conta as ideias de Echeverría (1995), a aceitação acrítica de um suposto método científico a-histórico e universal, independente de valores sociais, éticos e culturais, necessita ser questionada.

Um olhar mais aproximado para esta questão dos métodos científicos permite compreender que os cientistas abordam e resolvem os problemas com recurso à criatividade, imaginação, conhecimento prévio, espírito crítico e perseverança, aspectos empregados na resolução de problemas em outras áreas do conhecimento. Segundo a perspectiva sustentada por Oliva (2010):

Teorias não são elaboradas apenas com a matéria-prima dos fatos, mas também com a inventividade da razão humana. É a capacidade de processamento criativo que transforma sensações, percepções, observações e impressões em obras com valor estético, filosófico ou científico (p. 39).

Nessa perspectiva, os métodos empregados pela ciência não podem ser considerados procedimentos endurecidos, inflexíveis, pois, assim, estar-se-ia rejeitando 
as diferentes operações mentais (imaginação, intuição etc.) envolvidas na construção e implementação dos mesmos. Neste sentido, como afirmam Moreira e Ostermann (1993):

O método científico não é um procedimento lógico, algorítmico, rígido. Em outras palavras, o método científico não é uma receita, uma sequência linear de passos que necessariamente conduz a uma descoberta ou, pelo menos, a uma conclusão ou a um resultado. Na prática, muitas vezes, o cientista procede por tentativas, vai numa direção, volta, mede novamente, abandona certas hipóteses porque não tem equipamento adequado, faz uso da intuição, dá chutes, se deprime, se entusiasma, se apega a uma teoria. Enfim, fazer ciência é uma atividade humana, com todos os defeitos e virtudes que o ser humano tem, e com muita teoria que ele tem na cabeça (p. 114).

Este conjunto de processos mobilizados pelos cientistas - intuição, criatividade, imaginação, espírito crítico, entre outros - forneceu os subsídios necessários para intitular processo de criação científica a dimensão da natureza da ciência em questão no presente trabalho. À guisa de síntese, e com vistas à apresentação de uma categorização esquemática dos elementos discutidos, poder-se-ia agrupar os atributos do processo de criação científica mencionados em dois conjuntos, o primeiro geralmente associado a perspectivas de orientação positivista e o segundo usualmente associado a perspectivas de orientação pós-positivista (Coelho da Silva, 2007):

Atributos geralmente associados a uma perspectiva de orientação positivista. A experiência é a única fonte credível do conhecimento científico. O processo de criação científica consiste na capacidade de retirar interpretações corretas a partir da observação de factos e da análise de dados. O raciocínio indutivo é o processo mental geralmente utilizado. As observações ocasionais estão muitas vezes na origem das descobertas científicas. O processo de criação científica está restringido a um método único e universal, um processo algorítmico. O método é linear, sequencial, parte dos factos para as ideias, da observação para os conceitos. Implica a implementação de um conjunto de regras com precisão e rigor. A testagem experimental constitui o critério de validação do conhecimento científico. Depende da concordância com os factos.

Atributos geralmente associados a uma perspectiva de orientação pós-positivista. No processo de construção do conhecimento científico intervêm, por um lado, atos perceptivos que envolvem os sentidos, e por outro, o pensamento, a formação de ideias, atos em que intervém a razão. A razão orienta a experimentação e é, por sua vez, guiada pelos dados experimentais recolhidos. A intuição, a abstração, a percepção, a imaginação, a criatividade, a reflexão sistemática e o raciocínio são operações mentais utilizadas no processo de criação científica, sem ordem pré-estabelecida. O raciocínio analógico é um dos processos mentais utilizado pelos cientistas. Os processos adoptados pelos cientistas dependem dos seus próprios conhecimentos conceptuais e processuais bem como das tecnologias disponíveis. Os métodos científicos alteramse face à alteração do conhecimento científico e vice-versa. Os métodos seguidos são caracteristicamente de natureza holística, reflexiva, idiossincrática e de múltiplos passos sujeitos a monitorização. Os métodos são ramificados, sinuosos, incertos, flexíveis. Os 
problemas emergem no seio de um contexto teórico (p. 82).

Dando-se continuidade a esta seção introdutória, julgou-se pertinente tecer algumas considerações sobre o surgimento, desenvolvimento e propagação do mito do método científico no campo do ensino de ciências, uma vez que a investigação localizase neste âmbito.

A noção de uma série única de passos a ser seguida por todo investigador científico, "o método científico", é um dos mitos mais difundidos no ensino de ciências, tendo em vista a presença desta lista de passos em muitos manuais escolares. Tal lista pode apresentar variações entre os textos, mas em essência é constituída por alguns passos que devem se suceder na seguinte ordem: (a) definição de um problema; (b) aquisição de fundamentação; (c) formulação de hipóteses; (d) realização de observação; (e) teste de hipóteses; e (f) elaboração de conclusões (McComas, 2002).

Quanto às variações dessa lista, alguns autores reconhecem como ponto de partida a definição de um problema, outros, a observação. Por outro lado, alguns atribuem a finalização dos passos aos processos de tomada de ação ou publicação, enquanto outros consideram o término em passos anteriores, como a elaboração de conclusões. Os passos (c) e (e), mencionados no parágrafo acima, constituem o núcleo da maioria das listas, particularidade decorrente da influência do método hipotético-dedutivo nas visões sobre "o método científico". Em contrapartida, um método científico iniciado pela observação demarca a influência do método indutivista, fazendo da observação um processo necessário ao levantamento de hipóteses, negligenciando-se, portanto, os contributos de outras vias - discussões com outros pesquisadores, palestras, leitura de artigos e de livros didáticos etc. - para o levantamento de problemas científicos, no seio das diferentes disciplinas (Woodcock, 2014).

As atuais variações na composição desse suposto método podem ser parcialmente explicadas pela ausência de uma declaração canônica ao longo da história sobre o que seria a metodologia científica e pela inexistência de considerações consensuais sobre tal metodologia entre os filósofos da ciência contemporâneos (Woodcock, 2014). No tocante ao ensino de ciências, uma possível origem para a anuência frente a esse conjunto de passos a ser seguido foi considerada por McComas (2002):

A lista de múltiplos passos parece ter começado inocentemente quando Keeslar (1945) preparou uma lista de várias características associadas com a investigação científica, tais como estabelecer controles, manter registros precisos, realizar observações e medidas cuidadosas. Essa lista foi refinada em um questionário e submetida a investigadores para validação. Os itens que foram altamente ranqueados foram colocados em uma ordem lógica e fizeram parte da lista final de elementos associados com a investigação de problemas científicos. Tal lista foi rapidamente adotada por escritores de livros didáticos como a descrição de como a ciência é feita (p. 57, tradução nossa).

Outra possibilidade para o surgimento dessa visão deformada de ciência (Gil Pérez et al., 2001) - visão rígida (algorítmica, exata, infalível) - no âmbito do ensino é a forma como os resultados das pesquisas são apresentados nos artigos submetidos às 
revistas científicas. O estilo padronizado de redação supõe que os pesquisadores seguem um plano ou roteiro de pesquisa padrão (McComas, 2002). Convém explicitar alguns aspectos que motivaram a divulgação desse mito no ensino de ciências, que acaba por construir uma imagem mecânica e impessoal da atividade científica.

Apresentações pedagógicas de 'O Método Científico' muitas vezes fazem este parecer uma fórmula ou uma receita para fazer ciência, incentivando assim a impressão de ciência como um processo mecânico impessoal, isto é, presumivelmente motivado pelo desejo de apresentar a ciência como objetiva (ele também pode ter raízes pedagógicas na necessidade de um procedimento para guiar os alunos através de um projeto de ciências) (Woodcock, 2014, p. 2076, tradução nossa).

Tendo em conta as imagens deformadas sobre o processo de criação científica difundidas pelo ensino de ciências e manifestadas por futuros professores (ver, por exemplo, Oki, \& Moradillo, 2008; Rudge, Cassidy, Fulford, \& Howe, 2013), e a relevância de discussões sobre natureza da ciência em cursos de formação de professores, a presente investigação, efetuada no seio da disciplina Anatomia Humana, objetivou analisar o papel de uma estratégia de intervenção pedagógica, focalizada na história da ciência, na (re)construção de concepções de futuros professores sobre o processo de criação científica.

\section{Contexto Educativo e Descrição da Estratégia de Intervenção Pedagógica}

A estratégia de intervenção pedagógica foi desenvolvida no primeiro semestre do ano de 2015, no âmbito da disciplina Anatomia Humana, que compõe o elenco de componentes curriculares obrigatórios do segundo semestre de um curso noturno de Licenciatura em Ciências Biológicas. Este curso pertence a uma universidade pública, federal, localizada em uma cidade do interior de um estado da região Nordeste do Brasil.

No início do semestre, foram apresentadas as linhas gerais do projeto de pesquisa aos alunos para que compreendessem a relação entre as atividades de aprendizagem das quais participariam e a investigação. Em seguida, foi entregue a cada estudante uma cópia do Termo de Consentimento Livre e Esclarecido, com a finalidade de fornecer o mais amplo esclarecimento sobre a investigação a ser realizada, seus riscos e benefícios, para que a manifestação de vontade no sentido de participar (ou não) fosse efetivamente livre e consciente. Neste termo também constava o seguinte trecho: fui informado(a) de que posso me recusar a participar do estudo, ou retirar meu consentimento a qualquer momento, sem precisar justificar, e de que, por desejar sair da pesquisa, não sofrerei qualquer prejuízo durante a participação no componente curricular Anatomia Humana do curso de Biologia - Licenciatura. Ademais, destaca-se que o consentimento em participar da intervenção pedagógica não implicou em qualquer ganho ou subtração de pontos na disciplina. Os 33 alunos matriculados na disciplina avaliaram e assinaram o termo de consentimento livre e esclarecido. No entanto, apenas 22 foram incluídos na investigação, pois 11 alunos desistiram de cursar a disciplina ou não participaram de 
todas as atividades de aprendizagem.

O grupo de participantes do estudo era constituído por um quantitativo igual de cada sexo: onze homens e onze mulheres. Os alunos estavam distribuídos entre sete grupos de idade, estabelecidos de acordo com o Instituto Brasileiro de Geografia e Estatística (IBGE, 2010): (a) 15-19 anos: 1 aluno; (b) 20-24 anos: 4 alunos; (c) 25-29 anos: 8 alunos; (d) 30-34: 3 alunos; (e) 35-39: 2 alunos; (f) 45-49: 3 alunos; (g) 50-54: 1 aluno. A média de idade do grupo era de 30,4 anos (com desvio padrão de 9,4).

A implementação de atividades de aprendizagem focalizadas na exploração da história da ciência articuladas a atividades de aprendizagem centradas na reflexão metacognitiva sobre o processo de aprendizagem caracterizam, sumariamente, a intervenção pedagógica. Esta ação desenvolveu-se em um cenário educativo centrado na dialogicidade e na cooperação, com vistas a potencializar as interações entre alunos e entre alunos e professor, essencial para a (re)construção dos saberes, considerandose um paradigma socioconstrutivista (Bächtold, 2013; Jonnaert, 2012) e construtivista crítico (Kincheloe, 2006).

A intervenção pedagógica foi estruturada em torno da temática sistema circulatório humano, tendo em vista que a compreensão da circulação do sangue é considerada um dos eventos mais importantes da história da biologia (Agutter, \& Wheatley, 2008). Ademais, o entendimento desta temática é fundamental para a aprendizagem de outros conceitos biológicos como transporte e troca de materiais no corpo humano e hematose, e a compreensão das doenças cardiovasculares e do seu tratamento é, também, baseada em conceitos vinculados a esse sistema (Cheng, \& Gilbert, 2015).

A estrutura global da intervenção pedagógica, evidenciando os tipos de atividades de aprendizagem desenvolvidas - atividades de história da ciência, atividades de reflexão e atividade de síntese - é apresentada na Figura 1. Esta figura mostra as diferentes fontes de informação utilizadas nas atividades de aprendizagem focalizadas na exploração da história da ciência, sendo este um aspecto que as diferencia dos outros tipos de atividades. Destarte, uma variedade de tipos de textos foi empregada na intervenção pedagógica, inclusive uma fonte primária. Na Figura 1 também podem ser observados os nomes dos cientistas cujas ideias são abordadas - situados cronologicamente -, os conteúdos científicos trabalhados, o modo de resolução adotado em cada atividade de aprendizagem e o número de aulas dedicado a cada uma destas.

Em relação ao modo de resolução das atividades, sublinha-se que foram compostos cinco grupos de trabalho (pequenos grupos), dois formados por cinco alunos e três por quatro alunos. 


\begin{tabular}{|c|c|c|c|c|c|c|}
\hline \multicolumn{4}{|c|}{ Atividades de Aprendizagem } & \multirow[b]{2}{*}{$\begin{array}{l}\text { Conteúdo } \\
\text { científico }\end{array}$} & \multirow[b]{2}{*}{ Modo de resolução } & \multirow{2}{*}{$\begin{array}{l}\text { No de } \\
\text { aulas } \\
45 \mathrm{~min}\end{array}$} \\
\hline $\begin{array}{l}\mathrm{N}^{\circ} \text { das } \\
\text { At-HC }\end{array}$ & $\begin{array}{c}\text { Fonte de } \\
\text { informação }\end{array}$ & Cientista & $\begin{array}{l}\text { Época } \\
\text { Século }\end{array}$ & & & \\
\hline- & \multicolumn{3}{|c|}{ REFLEX̃̃o } & - & $\begin{array}{l}\text { Individual } \\
\text { Grupo turma }\end{array}$ & 2 \\
\hline 1 & $\begin{array}{l}\text { Excertos de } \\
\text { livros de História } \\
\text { da Ciência } \\
\text { e de artigos } \\
\text { científicos }\end{array}$ & $\begin{array}{l}\text { Erasístrato } \\
\text { Galeno } \\
\text { Fabricius }\end{array}$ & $\begin{array}{l}\text { II a.C. } \\
\text { II } \\
\text { XVII }\end{array}$ & $\begin{array}{l}\text { Vasos } \\
\text { sanguíneos: } \\
\text { morfofunção } \\
\text { Produção do } \\
\text { sangue }\end{array}$ & $\begin{array}{l}\text { Pequeno grupo } \\
\text { Grupo turma } \\
\text { Individual }\end{array}$ & 8 \\
\hline 2 & $\begin{array}{l}\text { Excertos de } \\
\text { livros de História } \\
\text { da Ciência } \\
\text { e de artigos } \\
\text { científicos }\end{array}$ & $\begin{array}{l}\text { Erasístrato } \\
\text { Galeno } \\
\text { Colombo }\end{array}$ & $\begin{array}{l}\text { II a.C. } \\
\text { II } \\
\text { XVI }\end{array}$ & $\begin{array}{l}\text { Morfologia } \\
\text { interna do } \\
\text { coração } \\
\text { Circulação do } \\
\text { sangue }\end{array}$ & $\begin{array}{l}\text { Pequeno grupo } \\
\text { Grupo turma } \\
\text { Individual }\end{array}$ & \\
\hline- & \multicolumn{3}{|c|}{ REFLEXÃO } & - & Individual & 2 \\
\hline 3 & Texto primário & $\begin{array}{l}\text { William } \\
\text { Harvey }\end{array}$ & XVII & $\begin{array}{l}\text { Circulação do } \\
\text { sangue } \\
\text { Produção do } \\
\text { sangue }\end{array}$ & $\begin{array}{l}\text { Pequeno grupo } \\
\text { Grupo turma } \\
\text { Individual }\end{array}$ & 4 \\
\hline 4 & $\begin{array}{l}\text { Experimento } \\
\text { histórico: } \\
\text { replicação }\end{array}$ & $\begin{array}{l}\text { William } \\
\text { Harvey }\end{array}$ & XVII & $\begin{array}{l}\text { Circulação do } \\
\text { sangue } \\
\text { Vasos } \\
\text { sanguíneos: } \\
\text { morfofunção }\end{array}$ & $\begin{array}{l}\text { Pequeno grupo } \\
\text { Grupo turma } \\
\text { Individual }\end{array}$ & 4 \\
\hline- & \multicolumn{3}{|c|}{ REFLEXÃO } & - & Individual & 2 \\
\hline 5 & Artigo científico & $\begin{array}{l}\text { Giulio } \\
\text { Bizzozero }\end{array}$ & XIX & $\begin{array}{l}\text { Produção do } \\
\text { sangue }\end{array}$ & $\begin{array}{l}\text { Pequeno grupo } \\
\text { Grupo turma } \\
\text { Individual }\end{array}$ & 4 \\
\hline 6 & Artigo científico & $\begin{array}{l}\text { Alfred Blalock } \\
\text { Helen Taussig } \\
\text { Vivien } \\
\text { Thomas } \\
\end{array}$ & $\begin{array}{l}\mathrm{XX} \\
\mathrm{XX} \\
\mathrm{XX}\end{array}$ & $\begin{array}{l}\text { Derivação } \\
\text { Blalock- } \\
\text { Taussig }\end{array}$ & $\begin{array}{l}\text { Pequeno grupo } \\
\text { Grupo turma } \\
\text { Individual }\end{array}$ & 4 \\
\hline 7 & $\begin{array}{l}\text { Texto de } \\
\text { divulgação } \\
\text { científica }\end{array}$ & Charles Drew & $\mathrm{XX}$ & $\begin{array}{l}\text { Transfusão } \\
\text { sanguínea }\end{array}$ & $\begin{array}{l}\text { Pequeno grupo } \\
\text { Grupo turma } \\
\text { Individual } \\
\end{array}$ & 4 \\
\hline- & \multicolumn{3}{|c|}{ SÍNTESE } & $\begin{array}{l}\text { Conteúdos } \\
\text { anteriores }\end{array}$ & $\begin{array}{l}\text { Pequeno grupo } \\
\text { Grupo turma }\end{array}$ & 4 \\
\hline- & \multicolumn{3}{|c|}{ REFLEXÃo } & - & Individual & 5 \\
\hline
\end{tabular}

Figura 1. Estrutura global da intervenção pedagógica

Nota: $\mathrm{N}^{\circ}$ das At-HC: número das atividades de História da Ciência de acordo com a ordem de implementação; a.C.: antes de Cristo; min: minutos. 
A constituição destes grupos foi a mesma durante toda a intervenção pedagógica, aspecto que permite classificá-los como grupos fixos. De acordo com Zabala (1998):

as equipes fixas oferecem numerosas oportunidades para trabalhar importantes conteúdos atitudinais. Sua estrutura também é apropriada para a criação de situações que promovam o debate e os correspondentes conflitos cognitivos e pela possibilidade de receber e dar ajuda, o que facilita a compreensão de conceitos e procedimentos complexos. Comprometem os alunos na gestão e no controle da aula e constituem um bom instrumento para promover a cooperação e a solidariedade (p. 125).

A intervenção pedagógica foi desenvolvida durante 43 aulas, cada uma constituída por um período de 45 minutos. As atividades de história da ciência foram introduzidas com a finalidade de contribuir para que os alunos (re)construíssem conhecimentos científicos (morfofunção do sistema circulatório humano) e conhecimentos epistemológicos (contexto da atividade científica, evolução do conhecimento científico e processo de criação científica). Neste trabalho, são abordados apenas aspectos atrelados à dimensão natureza da ciência no processo de criação científica.

As atividades de reflexão, de natureza metacognitiva, pretenderam contribuir para que os alunos tomassem consciência sobre seus conhecimentos, científicos e epistemológicos, em três momentos da estratégia de intervenção pedagógica: antes da intervenção; durante a intervenção; em um momento posterior a intervenção. Considerando-se o momento durante a intervenção e em caráter ilustrativo, segue uma questão que compôs uma das atividades de reflexão e que teve como foco o processo de criação científica: Explique o modo como este texto contribui para a: a.1) compreensão do processo de criação científica e dos métodos implicados nesta. Esta questão associase aos trabalhos desenvolvidos pelo filósofo natural William Harvey (1578-1657) e mencionados em seu texto primário trabalhado na intervenção.

A atividade de síntese teve o propósito de auxiliar os alunos na sistematização dos referidos conhecimentos (re)construídos ao longo da estratégia de intervenção pedagógica.

Para a melhor compreensão dos elementos destacados, é importante clarificar que a estratégia de intervenção pedagógica foi composta por sete atividades relacionadas à história da ciência, numeradas de acordo com a ordem de implementação:

(1) Interpretação de fragmentos da história da ciência sobre artérias, veias e produção de sangue (At-HC1);

(2) Interpretação de fragmentos da história da ciência: coração e pequena circulação (At-HC2);

(3) Interpretação de um texto primário de William Harvey (At-HC3);

(4) Reconstrução de um experimento histórico de William Harvey (At-HC4);

(5) Interpretação de um artigo científico sobre a vida e obra de Giulio Bizzozero (At-HC5);

(6) Interpretação de um artigo científico sobre a Derivação Blalock-Taussig (AtHC6); 
(7) Interpretação de um texto de divulgação científica sobre a biografia de Charles Richard Drew (At-HC7).

Na Figura 2 estão registrados os atributos presentes nas várias atividades de aprendizagem relacionadas ao processo de criação científica.

A imagem acerca do processo de criação científica, veiculada por meio da intervenção pedagógica caracteriza-se pela pluralidade de processos mobilizados pelos cientistas e pela possibilidade de alteração destes em função da época. A observação e a experimentação são os principais processos mencionados nas atividades de aprendizagem relacionadas à história da ciência. Nestas atividades, a observação está associada a procedimentos diversificados: vivissecação e dissecação de animais, dissecação de seres humanos, exame de esqueletos/cadáveres humanos e observação do corpo humano durante tratamentos cirúrgicos. A assunção de princípios éticos foi um fator que, em determinada época, conduziu à alteração dos procedimentos usados, nomeadamente a proibição da vivissecação de seres humanos. A experimentação é apresentada como um processo que permite a obtenção de evidências que contribuem para a interpretação dos fenômenos científicos, aspecto patente no seguinte trecho que introduz a terceira atividade de aprendizagem de história da ciência:

Harvey foi ensinar no Royal College of Physicians, onde ele apresentou seu artigo sobre como o coração atua e como o sangue se move. Ele não publicou sua teoria completa até 1628, pois foi necessário prover evidência experimental suficiente para apoiá-la. (AtHC3, sublinhado nosso)

A sétima atividade de aprendizagem não contemplou os processos de criação científica utilizados pelo cientista Charles Richard Drew, pois foi formatada, propositadamente, a partir de uma fonte de informação orientada para uma perspectiva mais externalista sobre a história da ciência. Segundo Ávila (2013), a perspectiva externalista tende a valorizar aspectos como relações institucionais, financiamentos, filiações políticas e condicionantes sociais. É relevante afirmar que a maioria das atividades de aprendizagem, com exceção da atividade quatro - voltada a reconstrução de um experimento histórico de William Harvey -, contemplou o contexto da atividade científica. Entretanto, em virtude dos limites textuais de um artigo científico, tal contexto não foi contemplado no presente trabalho. Nesse sentido, destaca-se como uma das limitações deste estudo o foco da intervenção pedagógica recair frequentemente sobre cientistas isolados, expostos numa ordem cronológica, estrutura que dificulta a compreensão das relações entre ciência, tecnologia e sociedade. 


\begin{tabular}{|c|c|c|}
\hline \multicolumn{2}{|c|}{$\begin{array}{l}\text { Atividades de aprendizagem de } \\
\text { história da ciência }\end{array}$} & \multirow[t]{2}{*}{ Processo de criação científica } \\
\hline Número & Cientistas & \\
\hline \multirow{3}{*}{1} & Erasístrato & $\begin{array}{l}\text { - Dissecação de cabras recém-nascidas } \\
\text { - Vivissecações de criminosos condenados }\end{array}$ \\
\hline & Galeno & $\begin{array}{l}\text { - Observação do corpo humano quando do tratamento cirúrgico de } \\
\text { gladiadores (Galeno era médico dos gladiadores) } \\
\text { - Dissecação de animais mortos (ex.: porcos, macacos) } \\
\text { - Exame de esqueletos/cadáveres humanos } \\
\text { - Realização de uma experiência para mostrar que as artérias não } \\
\text { continham ar. }\end{array}$ \\
\hline & Fabricius & - Dissecações \\
\hline \multirow[b]{2}{*}{2} & Galeno & \\
\hline & Colombo & $\begin{array}{l}\text { - Dissecação de seres humanos } \\
\text { - Vivissecação de animais vivos }\end{array}$ \\
\hline 3 & William Harvey & - Dissecação de animais \\
\hline 4 & William Harvey & $\begin{array}{l}\text { - Experiência concebida para compreender o movimento de sangue } \\
\text { no corpo humano. }\end{array}$ \\
\hline 5 & $\begin{array}{l}\text { Giulio } \\
\text { Bizzozero }\end{array}$ & $\begin{array}{l}\text { - Observação da medula óssea } \\
\text { - Realização de experimentos controlados com galinhas e pombos }\end{array}$ \\
\hline 6 & $\begin{array}{l}\text { Alfred Blalock } \\
\text { Helen Taussig } \\
\text { Vivien Thomas }\end{array}$ & $\begin{array}{l}\text { - Utilização de um modelo de coelho para estudar choque } \\
\text { traumático } \\
\text { - Experimentação para o alívio do estreitamento da aorta } \\
\text { - Experimentação com cães (inclui contagem do hematócrito) }\end{array}$ \\
\hline 7 & Charles Drew & - \\
\hline
\end{tabular}

Figura 2. Atributos do processo de criação científica patentes nas atividades de aprendizagem focalizadas na exploração da história da ciência

\section{Metodologia de Investigação}

O presente trabalho trata-se de um estudo de caso que pode ser definido como uma "investigação de uma unidade específica, situada em seu contexto, selecionada segundo critérios predeterminados e utilizando múltiplas fontes de dados, que se propõe a oferecer uma visão holística do fenômeno estudado" (Alves-Mazzotti, 2006, p. 650). A análise do papel da estratégia de intervenção pedagógica na (re)construção das concepções dos alunos sobre o processo de criação científica baseou-se na utilização de dois instrumentos de investigação: (1) atividades de aprendizagem; (2) roteiro da entrevista dos grupos focais.

As questões presentes nas atividades de aprendizagem que corporificaram a estratégia de intervenção pedagógica foram utilizadas como instrumentos de 
investigação, prática comum em pesquisas voltadas ao ensino de ciências, em âmbito universitário, como as desenvolvidas por Oki e Moradillo (2008), Almeida e Sorpreso (2010) e Zanotello (2011).

As entrevistas de grupos focais são utilizadas para recolher dados por intermédio da interação de um grupo de pessoas em torno de um tópico determinado pelo investigador, coordenador ou moderador do grupo (Morgan, 1996). A opção por esta técnica de entrevista se deveu à intenção de recolher as opiniões dos alunos sobre alguns aspectos relacionados à implementação da intervenção pedagógica. Foram realizadas três entrevistas do tipo grupo focal, com duração média de 90 minutos. O princípio da saturação dos dados (Morgan, 1997) norteou a realização das entrevistas, ou seja, o professor-investigador percebeu, durante a realização da terceira entrevista, que as informações começaram a se repetir, sendo, desta forma, desnecessário efetuar outras entrevistas.

As entrevistas do tipo grupo focal foram realizadas com cinco alunos cada, tendo por finalidade obter, em todas as entrevistas, opiniões de membros de cada um dos cinco grupos de trabalho (pequenos grupos) constituídos na intervenção pedagógica. Esta organização pretendeu enriquecer as entrevistas por meio da troca de experiências oriundas das situações vivenciadas em cada grupo de trabalho. Deve-se mencionar que a flexibilidade desta técnica de entrevista (ver Trad, 2009) permitiu, em determinados momentos, a exposição de posicionamentos associados a tópicos não diretamente associados à questão formulada aos entrevistados.

O processo de elaboração das questões presentes nas atividades de aprendizagem e no guião da entrevista dos grupos focais seguiu cinco etapas: (i) preparação da primeira versão das questões pelo professor-investigador; (ii) apresentação desta primeira versão a um especialista da área de ensino de ciências; (iii) revisão/reelaboração das questões de acordo com a opinião do especialista; (iv) sujeição da segunda versão ao especialista; (v) redação final das questões, de acordo com as considerações/sugestões finais. Desta forma, o especialista da área de Ensino de Ciências contribuiu para a validação interna da pesquisa. Entretanto, reconhece-se que a utilização de um maior número de especialistas seria mais apropriada. Outra limitação metodológica deste estudo é que os instrumentos de investigação cobrem um espectro restrito de aspectos associados aos processos de produção do conhecimento científico. A Figura 3 indica a relação entre os instrumentos de investigação (e as questões que os constituem) e as informações a obter.

A análise de conteúdo categorial (Bardin, 2000) das respostas dos alunos à questão 4 da atividade de aprendizagem As minhas ideias iniciais sobre morfofunção do sistema circulatório humano e natureza da ciência (atividade de reflexão 1) teve o intuito de identificar as concepções dos alunos sobre o processo de criação científica, no momento antes de ensino. A referida análise baseou-se em dois conjuntos de atributos do processo de criação científica, o primeiro geralmente associado a perspectivas de orientação positivista e o segundo usualmente associado a perspectivas de orientação pós-positivista (Coelho da Silva, 2007), caracterizadas na seção de introdução deste 
artigo. Posteriormente à análise de conteúdo, as respostas dos alunos foram integradas a uma das seguintes categorias de análise:

- Concepção positivista. Esta categoria incluiu as respostas que integraram atributos necessários para considerá-las de orientação positivista.

- Concepção pós-positivista. Esta categoria incluiu as respostas que integraram atributos necessários para considerá-las de orientação pós-positivista.

- Difícil categorização. Esta categoria incluiu as respostas que não integraram atributos necessários para considerá-las de orientação positivista ou pós-positivista.

- Ausência de resposta. Esta categoria inclui as questões não respondidas.

\begin{tabular}{|c|c|}
\hline Instrumentos de Investigação/Questões & Informação a obter \\
\hline $\begin{array}{l}\text { ATIVIDADE DE APRENDIZAGEM - REFLEXÃO 1 } \\
\text { Título da Atividade: As minhas ideias iniciais sobre morfofunção do sistema } \\
\text { circulatório humano e Natureza da Ciência } \\
\text { Questão: 4. Descreva o(s) processo(s) mobilizado(s) pelos cientistas } \\
\text { durante uma investigação. }\end{array}$ & $\begin{array}{l}\text { Concepções dos alunos } \\
\text { sobre o processo de } \\
\text { criação científica, no } \\
\text { momento antes de } \\
\text { ensino }\end{array}$ \\
\hline $\begin{array}{l}\text { ATIVIDADE DE APRENDIZAGEM - REFLEXÃO } 4 \\
\text { Título da Atividade: As minhas ideias sobre morfofunção do sistema } \\
\text { circulatório humano e Natureza da Ciência, ao final da intervenção } \\
\text { pedagógica } \\
\text { Questão: Com relação às questões } 4 \text { a } 10 \text { da atividade As minhas ideias } \\
\text { iniciais sobre morfofunção do sistema circulatório humano e Natureza da } \\
\text { Ciência, descreva que mudanças ocorreram na forma como inicialmente } \\
\text { pensava sobre cada questão. }\end{array}$ & $\begin{array}{l}\text { Concepções dos alunos } \\
\text { sobre o processo de } \\
\text { criação científica, no } \\
\text { momento pós-ensino }\end{array}$ \\
\hline $\begin{array}{l}\text { RoteIRO DA ENTREVISTA DOs GRUPOS FocAIS } \\
\text { 1. A utilização da história do sistema circulatório dificultou a aprendizagem } \\
\text { da anatomia humana? Por quê? } \\
\text { 2. O emprego da história do sistema circulatório contribuiu para a } \\
\text { compreensão sobre aspectos da natureza da ciência? Quais? }\end{array}$ & $\begin{array}{l}\text { Percepções dos } \\
\text { alunos sobre o papel } \\
\text { da estratégia de } \\
\text { intervenção pedagógica } \\
\text { na aprendizagem } \\
\text { dos conhecimentos } \\
\text { científicos e } \\
\text { epistemológicos }\end{array}$ \\
\hline
\end{tabular}

Figura 3. Relação Instrumentos de Investigação/Questões-Informação a obter

Para validar os dados, aplicou-se a seguinte sequência de quatro passos durante a análise do conteúdo: (i) primeira categorização das respostas dos alunos, de acordo com as categorias mencionadas; (ii) segunda categorização das respostas dos alunos, comparação com a primeira categorização efetuada e definição de uma nova categorização (terceira categorização); (iii) apreciação da terceira categorização por um especialista da área de Ensino de Ciências e definição de uma nova categorização (quarta categorização) das respostas dos alunos, após consenso entre as opiniões do especialista e do professor-investigador; (iv) sujeição desta quarta categorização a um segundo especialista da área de Ensino de Ciências 
e definição da quinta, e última, categorização. Reconhece-se que esta análise categorial implementada com a utilização de categorias pré-estabelecidas - concepções positivistas e pós-positivistas - foi por demais classificatória, não se abrindo à obtenção de categorias de maneira indutiva. Portanto, incorreu-se no risco de se ter pressionado a diversidade de significados expressos pelos alunos em direção as referidas categorias.

As concepções dos alunos sobre o processo de criação científica no momento pós-ensino foram analisadas com recurso às respostas dos alunos a uma questão da atividade de aprendizagem As minhas ideias sobre morfofunção do sistema circulatório humano e Natureza da Ciência, apresentada na Figura 3. Esta questão reflexiva foi introduzida na intervenção pedagógica com o intuito de avaliar, também, a análise que os alunos fizeram de suas concepções sobre o processo de criação científica, no momento antes de ensino, e a capacidade de os mesmos reconhecerem atributos de suas respostas que deveriam ser alterados para alinhá-las a uma concepção pós-positivista de ciência. A sequência de quatro passos, já mencionada, foi implementada na análise das respostas dos alunos a essa questão reflexiva, tendo-se como referência os mesmos conjuntos de atributos descritos por Coelho da Silva (2007, p. 82), também apresentados na introdução deste artigo.

A análise do papel da integração educativa da história da ciência na (re)construção das concepções dos alunos sobre o processo de criação científica fundamentou-se na comparação entre as concepções sustentadas nos momentos antes de ensino e pós-ensino. Este procedimento comparativo permitiu a identificação do processo de desenvolvimento das ideias dos alunos, classificado de acordo com as seguintes categorias:

- Progressão. Nesta categoria de análise foram incluídos os alunos que manifestavam, no momento antes de ensino, uma concepção acerca do processo de criação científica usualmente associada a perspectiva positivista e que passaram a manifestar, no momento pós-ensino, uma concepção associada a perspectiva pós-positivista.

- Progressão limitada. Nesta categoria de análise foram incluídos os alunos que não responderam a questão, no momento antes de ensino, e que passaram a manifestar, no momento pós-ensino, uma concepção associada à perspectiva positivista. Portanto, avaliou-se que estes alunos passam de uma situação em que não associavam ideia nenhuma ao processo de criação científica para uma situação em que são capazes de manifestar alguma opinião.

- Mesma posição. Nesta categoria de análise foram incluídos os alunos que manifestaram, no momento pós-ensino, a mesma categoria de análise apresentada no momento antes de ensino.

As respostas dos alunos inseridas na categoria progressão foram consideradas como indicativos de que a integração educativa da história da ciência contribuiu para a (re)construção das concepções dos alunos sobre o processo de criação científica.

A análise da Figura 3 indica que a avaliação do impacto da integração educativa da história da ciência na (re)construção das concepções dos alunos sobre o processo de 
criação científica associou-se, também, à análise de duas questões do roteiro da entrevista dos grupos focais. Tais questões permitiram analisar as percepções dos alunos sobre os contributos da estratégia de intervenção pedagógica na aprendizagem relacionada ao processo de criação científica. O conteúdo das respostas dos alunos a estas questões foi analisado qualitativamente com o intuito de identificar fragmentos dos discursos capazes de subsidiar o papel da intervenção pedagógica na (re)construção das concepções sobre o processo de criação científica.

\section{Avaliação do Papel da Intervenção Pedagógica na (Re)construção das Concepções dos Alunos sobre o Processo de Criação Científica}

Inicia-se esta seção com a apresentação e análise dos dados referentes às concepções dos alunos sobre o processo de criação científica. A Figura 4 mostra as concepções dos alunos sobre o processo de criação científica, nos momentos antes de ensino e pós-ensino.

A análise da Figura 4 indica que, no momento antes de ensino, nenhum dos alunos perfilhava concepções pós-positivistas de ciência, isto é, nenhum aluno considerava a pluralidade de processos mobilizados pelos cientistas ou a inexistência de um método científico linear. A maioria dos alunos sustentava concepções positivistas de ciência, indicando que: (a) o processo de criação científica restringe-se a um método único; (b) a observação é o único processo mobilizado pelos cientistas; (c) a testagem experimental é o critério de validação do conhecimento científico.

\begin{tabular}{|l|c|c|}
\hline \multirow{2}{*}{ Concepções acerca da ciência } & $\begin{array}{c}\text { Momento antes } \\
\text { de ensino }\end{array}$ & $\begin{array}{c}\text { Momento } \\
\text { pós-ensino }\end{array}$ \\
\cline { 2 - 3 } Concepção Pós-positivista & $\mathrm{f}$ & $\mathrm{f}$ \\
Pluralidade de processos mobilizados pelos cientistas & 0 & $\mathbf{9}$ \\
Inexistência de um método científico linear & 0 & 9 \\
\hline Concepção Positivista & $\mathbf{1 2}$ & $\mathbf{9}$ \\
O processo de criação científica restringe-se a um método único & 9 & 8 \\
A observação é o único processo mobilizado pelos cientistas & 1 & 1 \\
A intuição é o único processo mobilizado pelos cientistas & 1 & 0 \\
A testagem experimental constitui o critério de validação do & 1 & 0 \\
conhecimento científico & 6 & 3 \\
\hline Difícil categorização & 6 & 3 \\
Não são referidos processos de investigação & 4 & 1 \\
\hline Ausência de resposta & & \\
\hline
\end{tabular}

Figura 4. Concepções dos alunos sobre o processo de criação científica, nos momentos antes de ensino e pós-ensino $(\mathrm{n}=22)$

Nota: O somatório das frequências sem negrito, na categoria concepção pós-positivista, é superior ao número total de alunos desta categoria porque vários alunos indicaram mais de um aspecto que associa sua resposta a esta concepção. 
Entre os alunos que sustentavam concepções positivistas de ciência, predomina a ideia de que o processo de criação científica restringe-se a um método único, como pode ser observado nos dois exemplos que se seguem:

O cientista analisa o que se quer estudar e qual resultado ele pretende obter, após isso ele realiza experimentos e analisa o resultado, em seguida repete o experimento e estuda como chegou a tal resultado. (aluno A11)

Um cientista, ao investigar um patógeno, primeiro separa seu grau de contágio, após isso avalia os sintomas causados, daí, dependendo da situação, estabelece um perímetro para avaliar se o patógeno é, ou não, do local. Pesquisa qual seria o ponto zero, para daí, então, iniciar o estudo do patógeno, em si, patogenicidade, mecanismos moleculares de sobrevivência e reprodução, daí tenta desenvolver uma droga, que o inibe, ou tratamento, que sendo eficaz, inicia-se testes em animais de pequeno porte e, caso haja resultados positivos, os testes avançam para animais de grande porte até que se chegue ao organismo alvo, onde é testado incessantemente, se comprovada a sua eficiência é que é liberado para uso global. (aluno A21)

Nas respostas de ambos os alunos percebe-se a descrição de uma sequência de passos, que podem ser considerados como etapas de um único método científico. Os passos referidos pelo aluno A11 poderiam ser escritos como: identificação de um problema - previsão de resultados - experimentação - análise de resultados - repetição do experimento - nova análise de resultados. Por outro lado, o aluno A21 focaliza sua resposta em supostos passos relacionados ao desenvolvimento de fármacos: identificação das características de um patógeno - estudo de sua patogenicidade - desenvolvimento de um fármaco - testes in vitro - testes em animais de pequeno porte - testes em animais de grande porte - teste no espécime alvo - mais testes - liberação para uso global. Em uma investigação realizada no âmbito da disciplina História da Química, obrigatória para um curso de Licenciatura em Química, Oki e Moradillo (2008) também identificaram que a maioria dos alunos reconhecia a existência de um único método científico, no momento antes de ensino. Apesar das diferenças quanto às etapas, a ideia de uma lista de passos ordenados adotada pelos alunos do presente estudo pode estar associada às visões transmitidas pelos professores de ciências, que, muitas vezes, associam o emprego do "método científico" a uma forma segura de se chegar ao conhecimento científico (Moreira, \& Ostermann, 1993; Gil Pérez, et al., 2001). Além disso, diversos manuais escolares expõem uma lista de passos ordenados como essa, contribuindo, assim, para a construção do mito do "método científico" (McComas, 2002; Moreira, \& Ostermann, 1993).

A Figura 4 também mostra que quatro alunos não responderam à questão referente ao momento antes de ensino, provavelmente por falta de tempo, devido ao término do prazo para resolução da atividade, ou por ausência de compreensão do enunciado da questão. Além disso, seis alunos não se referiram aos processos de investigação, em suas respostas e, portanto, estas últimas foram incluídas na categoria 'difícil categorização'. Em caráter ilustrativo, seguem respostas em que não há referência aos processos de 
investigação mobilizados pelos cientistas:

Foco - objetivo - prós e contras - pesquisa - conclusão. (aluno A5)

Dependendo do que este cientista esteja investigando ele vai escolher o material que será pesquisado, o tempo, o espaço e o local. (aluno A8)

Reconhecimento pessoal. (aluno A19)

A análise da Figura 4, momento pós-ensino, mostra que nove alunos manifestaram concepções positivistas de ciência em relação ao processo de criação científica, sendo que a maioria desses deu respostas que indicam que o processo de criação científica restringe-se a um método único. Por outro lado, nove alunos passaram a manifestar concepções pós-positivistas ao indicarem, principalmente, a pluralidade de processos mobilizados pelos cientistas. Três alunos não se referiram a processos de investigação, enquanto um dos alunos não respondeu à questão referente ao momento pós-ensino.

Tais aspectos divergem dos resultados encontrados no estudo de Oki e Moradillo (2008), autores que também investigaram as potencialidades da aproximação entre história e filosofia da ciência e educação científica no âmbito do ensino superior. Após a participação na intervenção pedagógica elaborada por esses autores, todos os alunos "passaram a reconhecer a existência de vários métodos científicos e o caráter histórico desses métodos” (Oki \& Moradillo, 2008, p. 80). Esta expressiva modificação pode estar relacionada, entre outros aspectos, ao fato de estes autores terem utilizado um texto intitulado "sobre o ensino do método científico", de autoria de Moreira e Ostermann (1993), que explicita o caráter plurimetodológico da ciência. Provavelmente, alguns dos alunos que participaram da presente intervenção pedagógica precisariam de uma abordagem mais explícita e direta, em torno do processo de criação científica - como a implementada por Oki e Moradillo (2008) - para que modificassem suas concepções sobre essa dimensão da natureza da ciência. Neste sentido, avalia-se a relevância de se complementar a presente estratégia de intervenção pedagógica com outros materiais, em intervenções futuras.

Retornando a Figura 4, reafirma-se que nove alunos passaram a reconhecer a pluralidade de processos mobilizados pelos investigadores. O estudo de Teixeira, Freire Junior e El-Hani (2009), assentado na utilização da história e filosofia da ciência, no âmbito de uma disciplina relacionada à mecânica clássica, também evidenciou um aumento pós-ensino na diversidade de visões sobre os métodos científicos. Assim como no presente estudo, esses autores fizeram discussões sobre métodos científicos ao longo da intervenção pedagógica. Por exemplo, quando Galileu Galilei (1564-1642) foi citado, discutiu-se o uso mais sistemático da matemática e da experimentação (Teixeira, Freire Junior, \& El-Hani, 2009). Aspecto similar ocorreu na presente intervenção pedagógica, no contexto das discussões relacionadas a William Harvey (1578-1657), investigador que viveu no mesmo período histórico de Galileu e que passou a empregar a experimentação de forma mais sistematizada no contexto das ciências biológicas (Delizoicov, Carneiro, 
\& Delizoicov, 2004).

Os seguintes trechos de duas entrevistas com grupos focais, apresentados na Figura 5, ilustram as concepções de alguns alunos sobre as contribuições das atividades de aprendizagem para a reconstrução das concepções referentes ao processo de criação científica:

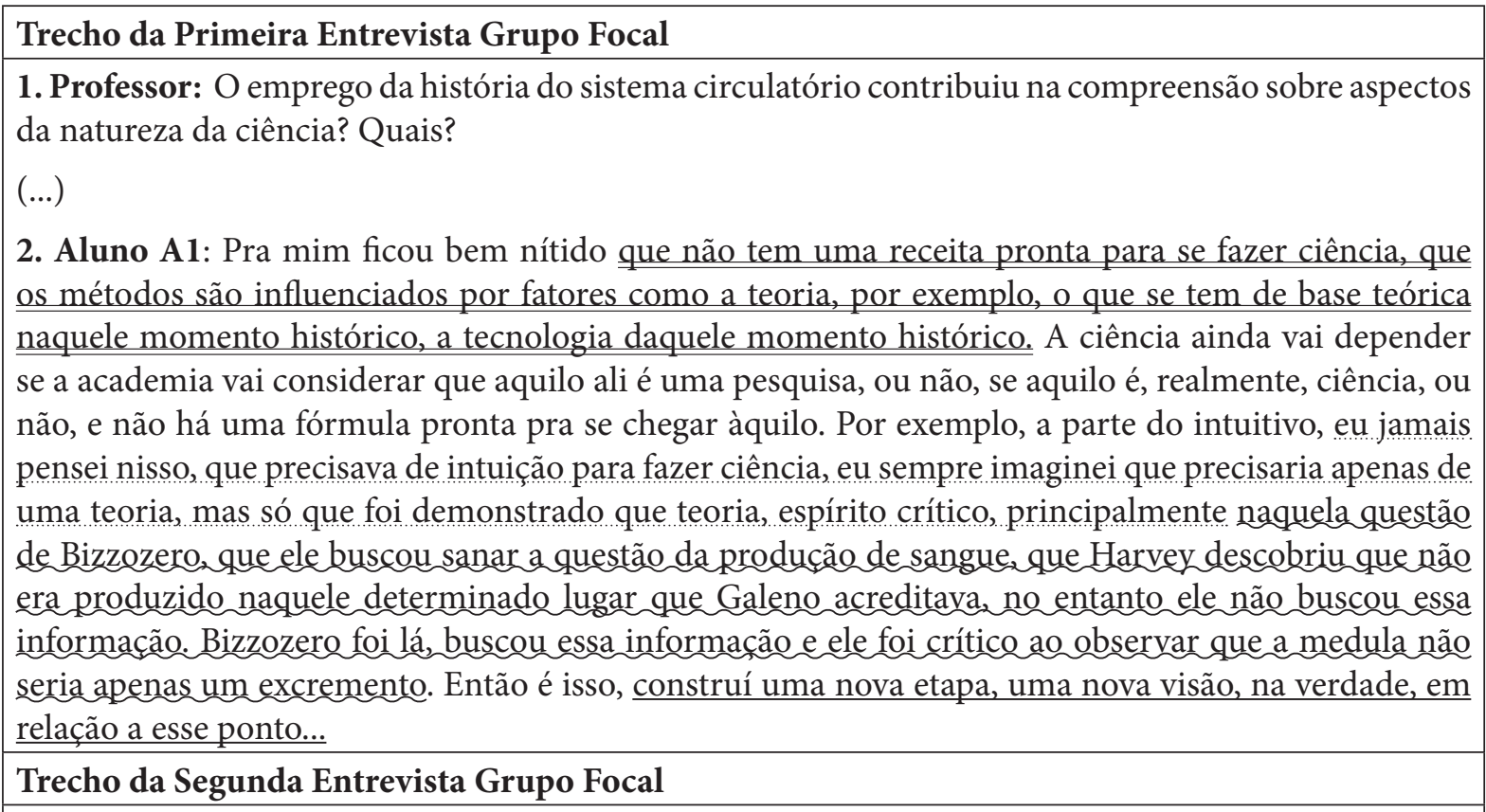

1. Professor: A utilização da história do sistema circulatório dificultou a aprendizagem da anatomia humana? Por quê?

(...)

2. Aluno A6: (...) falam, qual é a sua preferência? Assistir o filme ou ler o livro? Muitas pessoas preferem assistir ao filme, do que ler o livro, eu. O filme já lhe dá a imagem pronta do que seria e o livro você tem que criar a imagem na sua cabeça, desenhar o que seria aquela cena que tá sendo ali transcrita, e foi mais ou menos isso que a gente viu em alguns textos, a gente tinha que criar aquela representação do que eles imaginam porque eles também usavam, o cientista também utilizava a imaginação, a criatividade, pra determinar o que era aquilo, como no caso dos espíritos, do ar nas artérias, tudo aquilo foi questão de experimento, de criatividade, de raciocínio a respeito daquele processo científico...

$(\ldots)$

3. Aluno A14: É como o senhor falou, a anatomia trabalha muito com imagem, então a gente vê e tá tudo pronto, então, quando você trabalha a construção, você vê como a criatividade deles ao imaginar o que é que tinha lá dentro, se era sangue mesmo, se era ar, hoje a gente sabe que é sangue.

Figura 5. Trechos de entrevistas com grupos focais: concepções de alguns alunos sobre as contribuições das atividades de aprendizagem para a reconstrução das concepções referentes ao processo de criação científica

O relato do aluno A1, no trecho da primeira entrevista grupo focal, indica que a 
intervenção pedagógica contribuiu para que ele tivesse uma nova visão sobre o processo de criação científica (sublinhado). Este aluno declarou, de forma inequívoca, que não há uma receita pronta para se fazer ciência e que os métodos científicos são influenciados pelo conhecimento científico e tecnológico existente em determinado período histórico (sublinhado duplo). Ademais, esse aluno indicou alguns processos mobilizados pelos cientistas em suas investigações, como a intuição e a criticidade (sublinhado tracejado). Ao mencionar a questão da criticidade, o aluno A1 se referiu ao tópico produção de sangue - trabalhado na intervenção pedagógica por meio dos contributos de três cientistas citados pelo aluno, Galeno, Harvey e Bizzozero - para afirmar como Bizzozero foi crítico ao sustentar que a medula não seria apenas um excremento ósseo e sim o local onde o sangue seria produzido (sublinhado ondulado). No trecho da segunda entrevista do grupo focal, o aluno A6 ilustrou alguns dos processos mobilizados pelos cientistas em suas investigações, entre eles imaginação, criatividade e raciocínio. Para isso, o aluno A6 recorreu à questão dos elementos/substâncias transportados pelas artérias (sublinhado), discutida na atividade de aprendizagem intitulada Intepretação de fragmentos da História da Ciência sobre artérias, veias e produção de sangue (At-HC1). A discussão sobre os elementos/substâncias transportados pelas artérias também foi mencionada pelo aluno A14 para considerar a criatividade dos cientistas.

Destaca-se que todas as atividades de aprendizagem focadas na história da ciência, à exceção da atividade Interpretação de um texto de divulgação científica sobre a biografia de Charles Richard Drew (At-HC7), contemplaram os processos mobilizados pelos cientistas durante suas investigações. Como exemplo desses processos, pode-se destacar a observação, efetuada por meio de procedimentos diversificados, como: vivissecação e dissecação de animais, dissecação de seres humanos, exame de esqueletos/cadáveres humanos e observação do corpo humano durante tratamentos cirúrgicos.

Retornando a Figura 4, no que tange ao momento pós-ensino, percebe-se que três alunos não teceram considerações sobre o processo de criação científica, ou seja, não se referiram aos processos de investigação mobilizados pelos cientistas. Uma possível explicação para esse resultado pode estar relacionada à ausência de compreensão do que seriam os possíveis “processos mobilizados pelos cientistas”. As respostas do aluno A13, por exemplo, suportam esse ponto de vista:

"Estudo - pesquisa - descoberta - resultado" (aluno A13, momento antes de ensino)

"Sem alteração" (aluno A13, momento pós-ensino)

Por fim, um aluno não respondeu à questão referente ao momento pós-ensino, por motivo desconhecido.

$\mathrm{Na}$ continuidade, apresenta-se o processo de desenvolvimento das concepções dos 22 alunos acerca do processo de criação científica. Os dados contidos na Figura 6 representam o referido processo.

A análise da Figura 6 mostra que a maioria dos alunos manteve a mesma posição em relação às concepções sobre o processo de criação científica. Entre estes alunos, a 
maioria manifestou concepções positivistas no momento antes de ensino, enquanto a minoria apresentou respostas de difícil categorização em ambos os momentos, pois não indicou processos de investigação mobilizados pelos cientistas. Considerando-se que o conflito entre pontos de vista moderadamente divergentes é capaz de promover a revisão e reestruturação dos próprios pontos de vista no trabalho em grupo (Colomina, \& Onrubia, 2004), avalia-se que o estado inicial dos conhecimentos dos alunos - a maioria manifestava concepções positivistas e nenhum sustentava concepções pós-positivistas pode ter sido um fator que comprometeu a aprendizagem de alguns alunos.

\begin{tabular}{|c|l|l|l|}
\hline \multirow{2}{*}{ Alunos } & Concepção acerca do processo de criação científica & Desenvolvimento das \\
& momento antes de ensino & momento pós-ensino & conces \\
\hline A1 & Positivista & Pós-Positivista & Progressão \\
\hline A6 & Positivista & Pós-Positivista & Progressão \\
\hline A9 & Positivista & Pós-Positivista & Progressão \\
\hline A11 & Positivista & Pós-Positivista & Progressão \\
\hline A14 & Ausência de resposta & Pós-Positivista & Progressão \\
\hline A15 & Ausência de resposta & Pós-Positivista & Progressão \\
\hline A8 & Difícil categorização & Pós-Positivista & Progressão \\
\hline A17 & Difícil categorização & Pós-Positivista & Progressão \\
\hline A19 & Difícil categorização & Pós-Positivista & Progressão \\
\hline A3 & Positivista & Positivista & Mesma Posição \\
\hline A4 & Positivista & Positivista & Mesma Posição \\
\hline A10 & Positivista & Positivista & Mesma Posição \\
\hline A12 & Positivista & Positivista & Mesma Posição \\
\hline A16 & Positivista & Positivista & Mesma Posição \\
\hline A20 & Positivista & Positivista & Mesma Posição \\
\hline A21 & Positivista & Positivista & Mesma Posição \\
\hline A22 & Positivista & Positivista & Mesma Posição \\
\hline A2 & Difícil categorização & Difícil categorização & Mesma Posição \\
\hline A5 & Difícil categorização & Difícil categorização & Mesma Posição \\
\hline A13 & Difícil categorização & Difícil categorização & Mesma Posição \\
\hline A18 & Ausência de resposta & Ausência de resposta & Mesma Posição \\
\hline A7 & Ausência de resposta & Positivista & Progressão limitada \\
\hline
\end{tabular}

Figura 6. Desenvolvimento das concepções dos alunos acerca do processo de criação científica $(\mathrm{n}=22)$

Para ilustrar esse processo de manutenção de concepções, recorreu-se às respostas dos alunos A4 e A10 às questões referentes aos momentos antes de ensino e pós-ensino (Figura 7). 


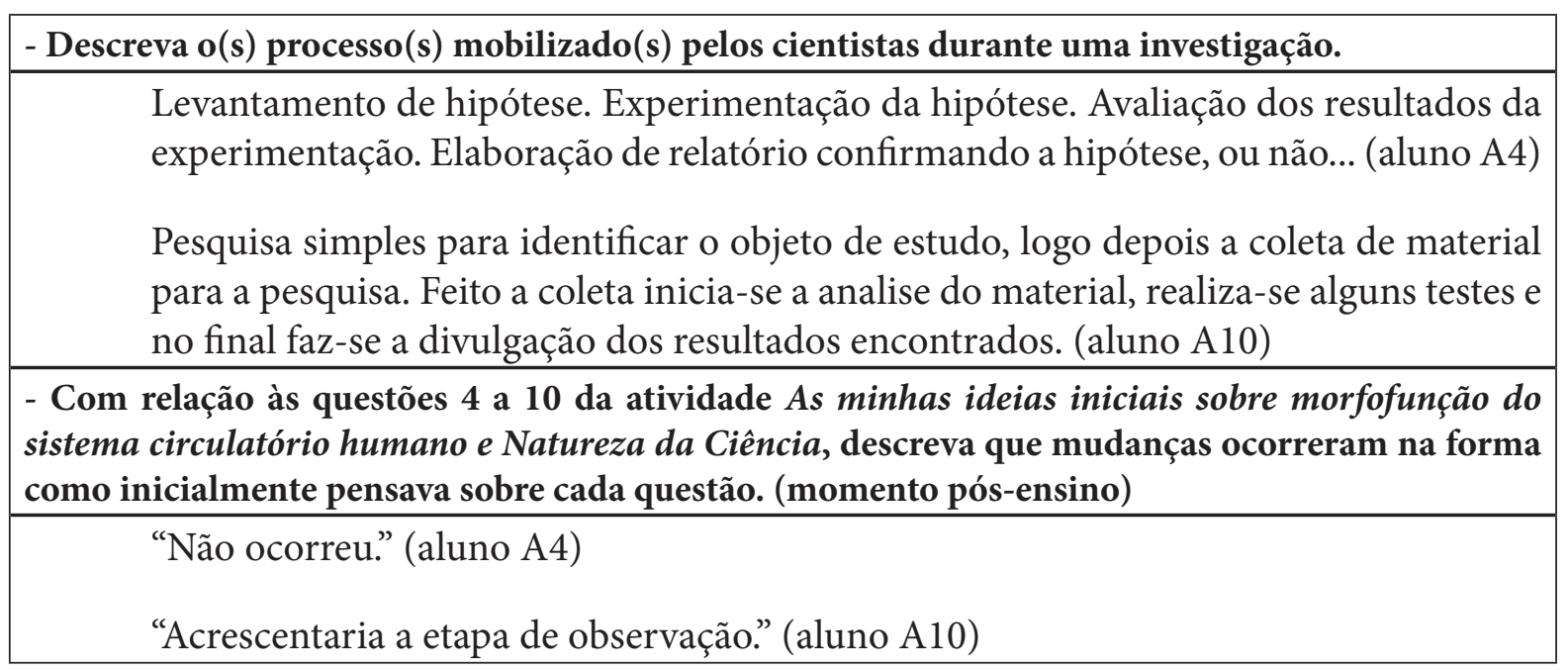

Figura 7. Respostas dos alunos A4 e A10 que ilustram manutenção de concepções

As respostas desses alunos no momento antes de ensino, indicam que os mesmos compreendiam o processo de criação científica como algo restrito a um método único. No momento pós-ensino, não ocorreram modificações. Considera-se que a resposta do aluno A10, no momento pós-ensino, apenas reforça a ideia de um método científico único, composto por um conjunto de etapas que devem ser rigidamente seguidas.

Por outro lado, a análise da Figura 5 também revela que dez alunos passaram por um processo de progressão em relação a suas concepções sobre o processo de criação científica. Para ilustrar esse processo, foram utilizadas as respostas dos alunos A14 e A15 às questões referentes ao momento pós-ensino, pois, no momento antes de ensino estes alunos não responderam à questão "Descreva o(s) processo(s) mobilizado(s) pelos cientistas durante uma investigação.”

Com relação às questões 4 a 10 da atividade As minhas ideias iniciais sobre morfofunção do sistema circulatório humano e Natureza da Ciência, descreva que mudanças ocorreram na forma como inicialmente pensava sobre cada questão. (momento pós-ensino)

Não respondi essa questão. Porém, hoje, depois de ler os textos, colocaria que existem vários processos de investigação realizados pelos cientistas, podendo haver mais de um método a ser utilizado e tendo influencia a criatividade, intuição e a visão crítica do problema. Também podem ser mobilizados por questões sociais, políticas e econômicas, para ajudar outras pessoas, como no texto de Drew, sobre o banco de sangue para ajudar na Guerra. (aluno A14)

Não respondi a questão, porém, hoje tenho uma visão de que há vários tipos de processos mobilizados durante uma investigação, por exemplo: dissecação, vivissecção, observação, imaginação, com a criação de instrumentos, mecanismos, que colaborem e contruam o conhecimento e os procedimentos científicos. (aluno A15)

Figura 8. Respostas dos alunos A14 e A15 quanto ao processo de progressão em relação a suas concepções 
A leitura das respostas desses dois alunos, que no início da estratégia de intervenção pedagógica não manifestavam qualquer tipo de posicionamento sobre os processos mobilizados pelos cientistas, indica que os mesmos passaram a se referir à existência de uma pluralidade de processos. Deve-se ressaltar que os processos mencionados pelos alunos vinculam-se, em sua totalidade, aos aspectos discutidos na estratégia de intervenção pedagógica. Este resultado indica o impacto positivo da intervenção sobre as aprendizagens dos alunos referentes ao processo de criação científica.

Por fim, a Figura 5 também mostra que o aluno A7 passou por um processo de progressão limitada em relação ao desenvolvimento das concepções acerca do processo de criação científica. Este aluno não respondeu à questão referente ao momento antes de ensino e, portanto, não manifestou nenhuma concepção. No entanto, ele respondeu à questão referente ao momento pós-ensino perfilhando uma concepção positivista, ao indicar a observação como o único processo mobilizado pelos cientistas, como pode ser verificado na Figura 9.

\begin{tabular}{|l|}
\hline $\begin{array}{l}\text { - Com relação às questões } 4 \text { a } 10 \text { da atividade As minhas ideias iniciais sobre morfofunção do } \\
\text { sistema circulatório humano e Natureza da Ciência, descreva que mudanças ocorreram na forma } \\
\text { como inicialmente pensava sobre cada questão. (momento pós-ensino) }\end{array}$ \\
\hline $\begin{array}{l}\text { Deveria ter respondido que a observação e a neutralidade do observador são processos } \\
\text { mobilizados pelos cientistas durante uma investigação. (aluno A7) }\end{array}$ \\
\hline
\end{tabular}

Figura 9. Respostas do aluno A7 ilustrando um processo de progressão limitada

Com base nas considerações anteriores e na resposta do aluno A7, pode-se afirmar que ele passou de uma situação em que não apresentava ideias sobre o processo de criação científica para uma situação em que foi capaz de manifestar alguma opinião. Neste sentido, o ensino teve efeito e houve progressão. No entanto, é uma progressão limitada porque não atinge a posição científica e filosófica aceita no presente estudo. Mas, ao menos, este aluno passou a reconhecer que a observação intervém no processo de criação científica. Deve-se salientar que o aluno A7 utilizou a expressão "neutralidade do observador" em sua resposta, posição diametralmente oposta aos aspectos considerados na intervenção pedagógica, em específico nas atividades Reconstrução de um experimento histórico de William Harvey (At-HC4) e Interpretação de um artigo científico sobre a vida e obra de Giulio Bizzozero (At-HC5), momentos em que se discutiu, explicitamente, a ausência de neutralidade nas observações científicas.

\section{Considerações Finais}

O objetivo da presente pesquisa foi analisar o papel de uma estratégia de intervenção pedagógica, baseada na história da ciência na (re)construção de concepções de futuros professores sobre o processo de criação científica. Nesta intervenção, utilizouse uma abordagem intermediária da história da ciência (ver Matthews, 1994), em que o processo histórico de construção de determinado conteúdo científico - no presente caso, o sistema circulatório humano - é desenvolvido recorrendo-se a um quadro teórico composto pela história intelectual, pessoal e social referente a este conteúdo. É 
importante salientar que tal intervenção, focalizada no sistema circulatório humano, também estabeleceu interfaces com outros conteúdos trabalhados na disciplina Anatomia Humana, como digestão, respiração e hematopoese, indicando que o tempo despendido nesta ação não comprometeu a abordagem de outros conteúdos desta disciplina.

As análises efetuadas no presente estudo evidenciam a manifestação, nos momentos antes de ensino e pós-ensino, de concepções positivistas de ciência, no que tange ao processo de criação científica. As concepções sustentadas pelos licenciandos foram: (i) o processo de criação científica restringe-se a um método único; (ii) a observação é o único processo mobilizado pelos cientistas; (iii) a intuição é o único processo mobilizado pelos cientistas; (iv) a testagem experimental constitui o critério de validação do conhecimento científico.

A comparação entre as concepções sustentadas pelos alunos nos momentos antes de ensino e pós-ensino indica que a estratégia de intervenção pedagógica contribuiu para que nove dos 22 alunos construíssem concepções pós-positivistas de ciência, ao reconhecerem a pluralidade de processos mobilizados pelos cientistas e/ou inexistência de um método científico linear. Nesta perspectiva, avalia-se que as concepções destes nove licenciandos se aproximaram da forma como o conhecimento científico é construído e produzido, segundo pesquisadores da educação científica (ver Gil Pérez et al., 2001), ou seja, por intermédio de diferentes metodologias e de operações mentais como imaginação, intuição e criatividade. Assim, considera-se que os elementos que corporificaram a estratégia de intervenção pedagógica - abordagem histórica do sistema circulatório humano, diversidade de fontes de informação mobilizadas, dialogia e reflexões sobre as aprendizagens - contribuíram para a (re)construção de concepções referentes a esta dimensão da natureza da ciência.

Sublinha-se que o trabalho efetuado em torno do processo de criação científica foi fruto de uma ação instrucional planejada e intencional, e por isto, explícita. Ademais os alunos foram mobilizados a refletir sobre esta dimensão da natureza da ciência por intermédio dos exemplos discutidos ao longo da intervenção, traço que também caracteriza seu caráter reflexivo (Rudge, \& Howe, 2009). Entretanto, avalia-se que uma abordagem pedagógica mais sistemática, explícita e reflexiva, acentuando as trocas intersubjetivas acerca do processo de criação científica, mediatizadas pelo emprego de recursos didáticos que tornem mais patente o caráter plurimetodológico da empreitada científica, poderá potencializar as aprendizagens dos licenciandos, no seio de uma intervenção focalizada na história do sistema circulatório humano.

Os resultados alcançados no presente estudo indicam a possibilidade de ampliação dos objetivos de aprendizagem levados em consideração, regularmente, em disciplinas de anatomia humana, contribuindo para o desenvolvimento da competência científica (Pedrinaci, 2012). Em geral, os objetivos dessa disciplina restringem-se, fundamentalmente, a aspectos relacionados aos conteúdos científicos, como exemplo: (i) identificar, nomear e descrever estruturas anatômicas do corpo humano e (ii) correlacionar forma e função das estruturas do corpo humano. Por outro lado, a presente 
investigação traz elementos que substanciam a inserção de outro objetivo de aprendizagem nesta disciplina: (re)construir concepções sobre uma dimensão da natureza da ciência: o processo de criação científica. A consecução deste objetivo relaciona-se à exploração de conteúdos epistemológicos (dimensões da natureza da ciência) que podem ser introduzidos na disciplina Anatomia Humana por meio da utilização da história da ciência. Desta forma, pode-se contribuir para o enriquecimento das aprendizagens dos alunos, para a compreensão da incerteza, do risco e da complexidade do mundo atual, decorrente da evolução acelerada da tecnociência.

O presente estudo mostra-se relevante quer no âmbito da educação em ciências quer no âmbito da investigação em educação em Ciências. $O$ texto que consubstancia o presente artigo constitui-se como um recurso formativo com o potencial de desencadear reflexões sobre o uso da história da ciência no ensino e na aprendizagem da Anatomia Humana pelos e com os professores da instituição de ensino superior universitário em que o estudo foi desenvolvido, incrementando-se, assim, a natureza da reflexão enquanto prática social. O estudo constitui um caso que também pode ser objeto de análise nos contextos de formação inicial e continuada de professores com a finalidade de promover a (re)construção das suas próprias concepções acerca do processo de criação científica, a consciencialização para a possibilidade de alunos dos ensinos Básico e Superior adotarem concepções deformadas acerca da natureza da ciência e a compreensão das potencialidades e limitações da história da ciência como recurso na reconstrução dessa concepções. O estudo pode, ainda, contribuir significativamente para os autores dos livros didáticos da área das ciências refletirem sobre a natureza das abordagens didáticas a adotar e o papel deste recurso didático na (re)construção das concepções acerca da natureza da ciência.

A pesquisa também contribui para a construção e consolidação da investigação no âmbito da operacionalização da história da ciência no ensino superior e, em particular, na formação de professores de Ciências Biológicas. Fornece uma estratégia pedagógica de cariz socioconstrutivista, originalmente idealizada para a integração da história da ciência no ensino da Anatomia Humana, que se mostrou relevante no desenvolvimento das aprendizagens acerca do processo de criação científica. A triangulação de dados, decorrentes da mobilização de instrumentos de investigação diversificados constitui uma abordagem metodológica que se recomenda por ter conferido maior validade à avaliação do impacto educativo da implementação da intervenção pedagógica. Salientase a análise do percurso experienciado pelos alunos, por meio da análise da ocorrência ou não de progressão nas concepções dos alunos, como uma abordagem metodológica relevante na compreensão do valor educativo da intervenção pedagógica. Além disso, os resultados obtidos fornecem um contributo significativo para o mapeamento das concepções dos alunos do ensino superior acerca do processo de criação científica. 


\section{Referências}

Abd-El-Khalick, F. (2005). Developing deeper understandings of nature of sience: The impact of a philosophy of science course on preservice science teachers' views ans instructional planning. International Journal of Science Education, 27(1), 15-42. https:// doi.org/10.1080/09500690410001673810

Agutter, P. \& Wheatley, D. (2008). Thinking about life: the history and philosophy of biology and other sciences. Dordrecht: Springer.

Alkhawaldeh, S. A. (2007). Facilitating conceptual change in ninth grade students' understanding of human circulatory system concepts. Research in Science \& Technological Education, 25(3), 371-385. http://dx.doi.org/10.1080/02635140701535331

Almeida, M. J. \& Sorpreso, T. P. (2010). Memória e Formação Discursivas na Interpretação de Textos por Estudantes de Licenciatura. Revista Brasileira de Pesquisa em Educação em Ciências, 10(1), 1-16.

Alves-Mazzotti, A. J. (2006). Uso e abusos dos estudos de caso. Cadernos de Pesquisa, 36(129), 637-651. http://dx.doi.org/10.1590/S0100-15742006000300007.

Ávila, G. C. (2013). Epistemologia em conflito: uma contribuição à história das Guerras da Ciência. Belo Horizonte: Fino Traço.

Bächtold, M. (2013). What Do Students "Construct" According to Constructivism in Science Education? Research in Science Education, 43(6), 2477-2496. https://doi. org/10.1007/s11165-013-9369-7

Bardin, L. (2000). Análise de conteúdo. Lisboa: Edições 70.

Chalmers, A. F. (1993). O que é ciência afinal? São Paulo: Brasiliense.

Cheng, M. M. \& Gilbert, J. K. (2015). Students' Visualization of Diagrams Representing the Human Circulatory System: The use of spatial isomorphism and representational conventions. International Journal of Science Education, 37(1), 136-161. https://doi.org/ 10.1080/09500693.2014.969359

Coelho da Silva, J. L. (2007). Natureza da Ciência em Manuais Escolares de Ciências Naturais e de Biologia e Geologia: imagens veiculadas e operacionalização na perspectiva dos professores e autores. (Tese de Doutoramento). Instituto de Educação e Psicologia da Universidade do Minho, Braga.

Colomina, R. \& Onrubia, J. (2004). Interação educacional e aprendizagem escolar: a interação entre alunos. In C. Coll; A. Marchesi \& J. Palacios (Orgs.). Desenvolvimento psicológico e educação: psicologia da educação escolar (pp. 280-293). Porto Alegre: Artmed. 
Delizoicov, N. C., Carneiro, M. H., \& Delizoicov, D. (2004). O movimento do sangue no corpo humano: do contexto da produção do conhecimento para o do seu ensino. Ciência \& Educação, 10(3), 443-460. https://doi.org/10.1590/S1516-73132004000300009.

Echeverría, J. (1995). Filosofia de la ciencia. Madrid: Akal.

Gil Pérez, D., Fernández, I., Carrascosa, J., Cachapuz, A. \& Praia, J. (2001). Para uma imagem não deformada do trabalho científico. Ciência \& Educação, 7(2), 125-153. http://dx.doi.org/10.1590/S1516-73132001000200001

Giordan, A. (2011). La historia de la biología y la geología y la enseñanza de las ciencias. In P. Cañal (Coord.). Biología y geologia: complementos de formación disciplinar (pp. 31-51). Barcelona: Editorial Graó.

Haack, S. (2012). Six signs of scientism. Logos \& Episteme, 3(1), 75-95. https://doi. org/10.5840/logos-episteme20123151

IBGE (2010). Sinopse do censo demográfico 2010, Brasil. Recuperado de http://www. censo2010.ibge.gov.br/sinopse/index.php?dados $=12$

Japiassú, H. \& Marcondes, D. (2001). Dicionário básico de Filosofia. Rio de Janeiro: Jorge Zahar Editor.

Jonnaert, P. (2012). Competências e socioconstrutivismo. Lisboa: Instituto Piaget.

Key, J. D., Keys, T. E., \& Callahan, J. A. (1979). Historical development of concept of blood circulation: an anniversary memorial essay to William Harvey. The American Journal of Cardiology, 43(5), 1026-1032. https://doi.org/10.1016/0002-9149(79)90370-9

Kincheloe, J. (2006). Construtivismo crítico. Mangualde: Edições Pedago.

Kuhn, T. (2000). A estrutura das revoluções científicas. São Paulo: Editora Perspectiva.

Lin, H. \& Chen, C. (2002). Promoting Preservice Chemistry Teachers' Understanding about the Nature of Science through History. Journal of Research in Science Teaching, 39(3), 773-792. https://doi.org/10.1002/tea.10045

Matthews, M. (1994). Science teaching: the role of history and philosophy of science. New York: Routledge.

McComas, W. (2002). The principles elements of the nature of science: dispelling the myths. In W. McComas (Org.). The nature of science in science education: rationales and strategies (pp. 53-70). New York: Kluwer academic publishers. https://doi.org/10.1007/0306-47215-5_3

Moreira, M. A. \& Osterman, F. (1993). Sobre o ensino do método científico. Caderno Catarinense de Ensino de Física, 10(2), 108-117.

Morgan, D. (1996). Focus Groups. Annual Review of Sociology, 22(1), 129-152. https:// doi.org/10.1146/annurev.soc.22.1.129

Morgan, D. (1997). Focus group as qualitative research. London: Sage. 
Oki, M. C., \& Moradillo, E. (2008). O ensino de história da química: contribuindo para a compreensão da natureza da ciência. Ciência \& Educação, 14(1), 67-88. https://doi. org/10.1590/S1516-73132008000100005

Oliva, A. (2010). Filosofia da Ciência. Rio de Janeiro: Jorge Zahar Editor.

Pedrinaci, E. (2012). El ejercicio de una ciudadanía responsable exige disponer de cierta competencia científica. In E. Pedrinaci (Coord.). 11 ideas clave: el desarrollo de la competencia cientifica (pp. 15-37). Barcelona: Editorial Graó.

Rivero, A. \& Wamba, A. (2011). La naturaleza de la ciencia y construcción del conocimiento científico. La naturaleza de la ciencia como objetivo de enseñanza. In $\mathrm{P}$ Cañal (Coord.). Biología y geologia: complementos de formación disciplinar (pp. 9-30). Barcelona: Editorial Graó.

Rudge, D. W. \& Howe, E. M. (2009). An explicit and reflective approach to the use of history to promote understanding of the nature of science. Science \& Education, 18(5), 561-580. https://doi.org/10.1007/s11191-007-9088-4

Rudge, D. W., Cassidy, D. P., Fulford, J. M., \& Howe, E. M. (2013). Changes Observed in Views of Nature of Science During a Historically Based Unit. Science \& Education, 23(9), 1879-1909. https://doi.org/10.1007/s11191-012-9572-3

Teixeira, E. S., Freire Júnior, O. \& El-Hani, C. N. (2009). A influência de uma abordagem contextual sobre as concepções acerca da natureza da ciência de estudantes de física. Ciência \& Educação, 15(3), 529-556. https://doi.org/10.1590/S1516-73132009000300006

Trad, L. (2009). Grupos focais: conceitos, procedimentos e reflexões baseadas em experiências com o uso da técnica em pesquisas de saúde. Physis: Revista de Saúde Coletiva, 19(3), 777-796. https://doi.org/10.1590/S0103-73312009000300013

Woodcock, B. (2014). “The Scientific Method" as Myth and Ideal. Science \& Education, 23(10), 2069-2093. https://doi.org/10.1007/s11191-014-9704-Z

Zabala, A. (1998). A Prática Educativa: como ensinar. Porto Alegre: Artmed.

Zanotello, M. (2011). Leituras de textos originais de cientistas por estudantes do ensino superior. Ciência \& Educação, 17(4), 987-1013. https://doi.org/10.1590/S1516731320110004000 


\section{Gabriel Ribeiro}

${ }^{\circledR}$ http://orcid.org/0000-0002-7150-9520 Universidade Federal do Recôncavo da Bahia Cruz das Almas, Bahia, Brasil fta_gabrielribeiro@yahoo.com.br

José Luís de Jesus Coelho da Silva

${ }^{1}$ http://orcid.org/0000-0001-7173-6566 Universidade do Minho Braga, Portugal zeluis@ie.uminho.pt

Submetido em 06 de Julho de 2018 Aceito em 07 de Janeiro de 2019 Publicado em 04 de Maio de 2019 